\title{
Figural preference and the visual field'
}

\section{H. R. SCHIFFMAN ${ }^{2}$ RUTGERS UNIVERSITY}

Three experiments tested a hypothesis that the shape and relative dimensions of the binocular visual field determine a preference for rectangles possessing dimensions similar to those of the golden section. The results were that Ss horizontally oriented the rectangles they had drawn in correspondence with the shape of the binocular visual field but when $S$ s chose the most pleasing rectangles there was no significant preference for rectangles whose long side was horizontal. For all experiments there was little preference for rectangles whose ratio of short to long side approximated the golden section. There was some evidence that the placement of the rectangles with respect to the background affects preference.

The golden section refers to a unique geometric proportion which, in the case of a rectangle, requires that the shorter side be about $0.618 \pm$ of the longer. ${ }^{3}$ Concern with the golden section as an empirically demonstrable preference among rectangles goes back at least several decades. However, a review of early research indicates that, on the whole, the results are ambivalent (Woodworth, 1938; Ogden, 1937). There is some evidence for the golden section as a modal choice, but with a broad modal value and a great deal of individual variation. At this point it must be concluded that a stable preference for rectangles possessing the proportions of the golden section has yet to be demonstrated.

Confounding this conclusion is a recent hypothesis advanced to explain the supposed preference for rectangles whose dimensions are approximations of the golden section (Stone \& Collins, 1965). Briefly, it is a perimetric hypothesis in that it is based on the relation of the area of the binocular field to a rectangle possessing dimensions of the golden section. The authors of the hypothesis found that an "average rectangle" of rectangles drawn within and around a chart of the binocular visual field possesses $90 \%$ of the area within the outline of the binocular field and is a rectangle whose ratio of length to width is 0.665 . According to the hypothesis it is the correspondence between the relative dimensions of the binocular visual field and the golden section that accounts for the preference of the latter in figural displays. Though not cited by the authors, it is of particular relevance that the fitted rectangle is horizontally oriented with respect to the long side. It follows that, if a preference for a particular ratio of long to short side is determined by visual field dimensions, then the orientation of the figure should also coincide with the field's horizontal orientation. This horizontal orientation also corresponds to a map of the visual field during a short-time visual search, an ovaloid with the long axis the horizontal one (Chaiken, Corbin, \& Volkmann, 1962).

Since a clear preference for rectangles of the golden section dimensions has not been consistently shown, the hypothesis should be restated: The general shape of the binocular visual field determines a preference for similarly oriented rectangles possessing similar ratios of length to width. Accordingly, two figural preferences should be tested: a preference for rectangles possessing the dimensions of the golden section and a preference for rectangles whose long side is horizontal with respect to the viewer. This study was performed to test for these preferences in two kinds of situations: one in which Ss draft their own figures and one in which Ss choose a figure from a series of rectangles that differ in the orientation of the long side and in ratios of short to long side.

\section{Subjects \\ EXPERIMENT}

The Ss were 115 male students from an introductory course in experimental psychology.

\section{Apparatus and Procedure}

The Ss were tested in a classroom situation and made their responses at their desks on square sheets of white paper, $12.70 \mathrm{~cm}$ a side. The instructions were to "draw the most aesthetically pleasing rectangle that you can on the sheet of paper." After completion, the Ss were instructed to orient the figure (horizontally or vertically with respect to the long side) in the most pleasing position. This latter procedure was instituted to insure that what was scored as the preferred orientation was not due to ease in drawing horizontal or vertical lines.

\section{Results}

Slightly less than $90 \%$ (103 out of the $115 \mathrm{Ss}$ ) oriented their rectangles with the long side horizontal. Nine chose a vertical orientation and three Ss drew approximately square figures. The average ratio of smaller to larger side for the 103 horizontally oriented rectangles was .489 , with a median of .500 , a modal value between .490 and .501 , and a standard deviation of .167 . The mean ratio of the vertically oriented rectangles was $\mathbf{4 8 5}$. These findings closely replicate those obtained in earlier studies (Davis, 1933; Schiffman, 1966).

\section{EXPERIMENT 2}

The results, though consistent with respect to predicted orientation, call into question the existence of a preference for the golden section. One explanation may lie in the means by which figural preferences were obtained; there may be a distinction between drafting a preferred rectangle and choosing a rectangle from a number of rectangles varying in ratios of length to width. Accordingly, the second experiment was performed to assess figural preferences when viewers chose rather than drafted.

\section{Subjects}

Twenty-five males, volunteers from an introductory psychology course, served as the Ss. Postexperimental comments from each $S$ indicated that they were naive to the phenomenon of a golden section preference.

\section{Apparatus}

The stimuli were 12 rectangles cut from white poster board. Six rectangles were always oriented with long side horizontal and six were oriented with the long side vertical. The longest dimension was constant at $12.70 \mathrm{~cm}$ for all stimuli. The short dimension varied for the six vertically and six horizontally oriented stimuli so that the ratios of the short to the long dimension were $.318, .418, .518, .618$ (golden section), .718 , and .818. The stimuli were shown at eye level against a square black screen, $60.96 \mathrm{~cm}$ a side, located about $1 \mathrm{~m}$ from $\mathrm{S}$. An extending lip of $2.50 \mathrm{~cm}$ on the bottom of the screen supported the stimuli; this resulted in the geometric centers of the horizontal and vertical rectangles being at different vertical heights. (The stimuli were also at the bottom rather than at the center of the screen.) The stimuli were shown in normal room lighting. 
Table 1

Per Cent of Preferences from Pairings of each Rectangle with all other Rectangles

\begin{tabular}{lcc}
$\begin{array}{c}\text { Ratio of short } \\
\text { to long side }\end{array}$ & $\begin{array}{c}\text { \% preferences } \\
\text { long side vertical }\end{array}$ & $\begin{array}{c}\text { \% preferences } \\
\text { long side horizontal }\end{array}$ \\
\hline .318 & 47.6 & 42.5 \\
.418 & 56.0 & 51.2 \\
.518 & 63.6 & 54.9 \\
$.618^{*}$ & 57.4 & 50.1 \\
.718 & 55.2 & 40.0 \\
.818 & 43.6 & 37.0 \\
\hline
\end{tabular}

* ratio of golden section

\section{Procedure}

Each S was individually tested. All stimuli were paired with all other stimuli resulting in 66 comparisons $[n(n-1) / 2]$. Time and space errors were minimized by counterbalancing the order of presentation; each rectangle appeared equally often on the left and on the right side. The duration of presentation was about 5 sec. The instructions were: "This is an experiment in aesthetic preference. Pairs of rectangles will be shown against this screen. Carefully examine the two rectangles and choose the one that appears the most aesthetically pleasing." The Ss gave their choices by indicating the location of the preferred figure (left or right).

\section{Results}

The results are given in Table 1 . Each value represents the per cent of preferences for each rectangle. No ratio shows any significant advantage over the remaining ratios though the most preferred ratio was .518 . There was also no preference for a horizontally oriented rectangle; rather, there was an overall preference (nonsignificant) for the vertically oriented figures; summing over rectangles yields a $57.3 \%$ preference for the rectangles whose long side was vertical.

\section{EXPERIMENT 3}

Experiment 3 was designed to examine two procedural factors that may have influenced the failure to obtain a preference for the golden section in Experiment 2. They were the mode of stimulus presentation and the number of comparisons. Accordingly, the least preferred rectangle of Experiment 2 was omitted in the present experiment resulting in 45 comparisons (a reduction of 21 comparisons from Experiment 2). The second factor considered was the placement of the figures; the geometric centers of all rectangles were located at the same vertical height and were centered with respect to the background.

\section{Subjects}

The Ss were 20 males, volunteers from an introductory psychology course. All Ss were unfamiliar with the notion of the golden section.

Table 2

Per Cent of Preferences from Pairings of each Rectangle with all other Rectangles

\begin{tabular}{lcc}
$\begin{array}{l}\text { Ratio of short } \\
\text { to long side }\end{array}$ & $\begin{array}{c}\text { \% preferences } \\
\text { long side vertical }\end{array}$ & $\begin{array}{c}\text { \% preferences } \\
\text { long side horizontal }\end{array}$ \\
\hline 318 & 65.0 & 67.8 \\
.418 & 65.0 & 61.1 \\
.518 & 48.3 & 48.9 \\
$.618^{*}$ & 37.2 & 42.2 \\
.718 & 29.4 & 35.0 \\
\hline
\end{tabular}

* ratio of golden section

\section{Apparatus}

The stimuli were 45 positive transparencies made from pairings of 10 rectangles. The rectangles were white figures and were photographed against a gray-green background. The geometric centers of all rectangles were placed at the same vertical height and were centered with respect to the projected image. The same ratios of short to long side used in Experiment 2, with the exclusion of .818 , were used in the present experiment. The slides were shown from a $500-\mathrm{W}$ projector and cast a $56 \times 38 \mathrm{~cm}$ image at eye level on a rear-projection screen located about $1 \mathrm{~m}$ from $\mathrm{S}$.

\section{Procedure}

Each $S$ faced the front of the rear-projection screen and was individually tested. Each rectangle appeared equally often on the left and right sides. Duration time was $5 \mathrm{sec}$ per slide. The instructions were the same as in Experiment 2.

\section{Results}

The per cent of preferences for each rectangle is given in Table 2 . Though no ratio was significantly preferred, there was a tendency to prefer the narrow rectangles. For the horizontal. vertical comparison, the re was a $51 \%$ preference for the vertically oriented rectangle.

\section{DISCUSSION}

Taken as a whole these findings provide no evidence for the golden section as a preferred ratio or for any mathematical ratio as a governing factor in rectangle preference. This is consistent with a number of earlier discussions of the golden section as a demonstrable preference. Thus the shape of the binocular visual field does not appear to determine a preference for a rectangle with a unique ratio of length to width.

With respect to an orientation preference, the difference between the results in Experiment 1 and Experiments 2 and 3 indicates that drafting a preferred rectangle and chonsing preferred rectangle from a series of rectangles involu differem

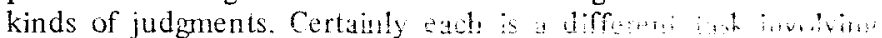
many uncontrolled variables not found in the other.

The discrepant results between Experiments $=$ an ? at a: most reasonably attributed to the placement of the stimuli. A narrow rectangle is apparently more favored when th to chicul with respect to the background than when it is placed atyanst the bottom of a background screen. Of course these results are hound to these experimental conditions. Othe procedures mb! apparatuses may enable the manifestation of the golden section preference, but it is clear that it is not an easily donivistiable phenomenon. It may be the case that systematically varying ! number of procedural variables will yicld a preference for 1 number of ratios.

On the basis of the available findings it must be concluded thit the metric properties of the golden section form a ralio that liss no reference to figural preference or, at best, that the golden section preference for rectangles is an extrencly fragile phenomenon.

Though its intrusion in the area of figural preferences may the questionable, a perimetric consideration of the visual fiel! has been shown to be an influential deteminant in other perepinal areas. For example, Künnapas $(1957,1959)$ has demonstrated that artificially manipulating the shape of the binocular visual field affects illusory phenomena. Doubless, a perimetric hypothesis can be applied profitably to other aspects of perception; rather than delimit it, perhaps the perimetric hypothesis should be extended to more stable phenomena.

\section{REFERENCES}

CHAIKIN, J. D., CORBIN, H. H., \& VOLKMANN, J. Malpping a lide at short-time visual search. Science, 1962, 138, 1327-1328. 
DAVIS, F. C. Aesthetic proportion. American Journal of Psychology, 1933, 45, 298-302.

KU'NNAPAS, T. M. The vertical-horizontal illusion and the visual field. Journal of Experimental Psychology, 1957, 53, 405-407.

KUNNAPAS, T. M. The vertical-horizontal illusion in artificial visual field. Journal of Psychology, 1959, 47, 41-48.

OGDEN, R. M. Naive geometry in the psychology of art. American Journal of Psychology, 1937, 49, 210-211.

SCHIFFMAN, H. R. Golden section: Preferred figural orientation. Perception \& Psychophysics, 1966, 1, 193-194.

STONF, L. A., \& COLLINS, L. G. The golden section revisited: A perimetric explanation. American Journal of Psychology, 1965, 78, 503-506.
WOODWORTH, R. S. Experimental psychology. New York: Holt, 1938.

\section{NOTES}

1. This research was supported by Grant 07-2109 from the Rutgers Research Council of Rutgers University. Robert Blaustein tested Ss and helped with the data anlysis.

2. Address: Department of Psychology, Rutgers University, New Brunswick, New Jersey 08903.

3. Specifically, the golden section refers to the geometric proportion, $1: X=X: 1-X$, or the whole is to the larger part as the larger part is to the smaller.

(Accepted for publication January 20, 1969.) 